\title{
As “visões” de Tirésias: arte, música e compreensão
}

\author{
The "Visions" from Tirésias: Art, Music and Understanding
}

\author{
Gerson Luís Trombetta \\ Universidade de Passo Fundo, Passo Fundo, RS, Brasil. \\ gersont@upf.br
}

Resumo: 0 artigo analisa as relações possíveis entre os sistemas simbólicos da arte e da ciência. Ainda que existam especificidades em cada uma dessas expressões do pensamento humano, ambas são experiências de compreensão do mundo e portadoras de conteúdos de verdade. 0 artigo segue a posição construtivista de Nelson Goodman, que recusa qualquer hierarquia entre as formas de conhecimento. Os traços gerais de sua epistemologia demonstram o valor cognitivo da arte e da música, recusando a noção de que experiências com elas sejam apenas prática de "habilidades" ou ocasiões "emocionais".

Palavras-chave: arte, música e ciência; compreensão de sistemas simbólicos; construtivismo de Nelson Goodman.

Abstract: The article analyzes the possible relationships between science and symbolic systems of art. Despite the differences between these two ways to express human thinking, both aim at understanding the world and both contain the truth. It discusses the constructivist approach of Nelson Goodman, which rejects any kind of hierarchy between different forms of knowledge. The general characteristics of his epistemology illustrate the cognitive value of art and music, refuting the notion that considers experiences with them as merely ways to practice "skills" or "emotional" occasions. Keywords: art, music and science; understanding of symbolic systems; constructivism of Nelson Goodman.

Data de recebimento: 08/02/2016

Data de aprovação final: 15/04/2016 
"É horrível! Temo que Tirésias, mesmo cego, tenha enxergado [...]" (Édipo)

\section{Breve abertura}

Logo no início da tragédia "Édipo Rei", Sófoclesintroduz um personagem crucial para explicar a teia de atribulações que cercam Édipo. 0 intrigante personagem é Tirésias, o velho adivinho que chega conduzido por um menino. Interessado em descobrir o assassino do Rei Laio e salvar Tebas, Édipo interpela Tirésias sobre o que sabe a respeito. Ciente da verdade dura que aguarda Édipo, o adivinho reluta: “Pobre de mim! Como é terrível a sapiência quando quem sabe não consegue aproveitá-la! Passou por meu espírito essa reflexão, mas descuidei-me, pois não deveria vir. [...]Manda-me embora! Assim suportarás melhor teu fado e eu o meu”. Diante de um resistente Tirésias, Édipo não vê outro caminho a não ser elevar o tom: "Que dizes? Sabes a verdade e não a falas? Queres trair-nos e extinguir nossa cidade?".

O diálogo prossegue ríspido, com Tirésias mantendo a recusa em dizer o que sabe: "Não quero males para mim nem para ti. Por que insiste na pergunta? É tudo inútil. De mim, por mais que faças nada saberás." A paciência de Édipo se esgota: "Não, falarás, então, pior dos homens maus, capaz de enfurecer um coração de pedra? Persistirás, inabalável, inflexível?" É então que Édipo usa o argumento derradeiro, acusando Tirésias de ser o articulador do crime, dada sua recusa em colaborar: "Pois bem. Não dissimularei meus pensamentos, tão grande é minha cólera. Fica sabendo que em minha opinião articulaste o crime e até o consumaste! Apenas tua mão não o matou. $\mathrm{E}$ se enxergasses eu diria que foste o criminoso sem qualquer ajuda!". É neste momento que Tirésias "vira o jogo"; de "encurralado" pelas insinuações maldosas passa a assumir a condição de agente da "impávida verdade" e põe "na mesa" aquilo que Édipo jamais sonhou: "Pois ouve bem: és o assassino que procuras!"; e, na sequência, referindo-se ao casamento incestuoso com Jocasta: “Apenas quero declarar que, sem

${ }^{1}$ Utilizamos, para esse artigo, a tradução de Mário da Gama Kury, cuja referência completa está no final. As citações que aqui constam encontram-se entre as páginas 34 e 37 do referido livro. 
saber, manténs as relações mais torpes e sacrílegas com a criatura que devias venerar, alheio à sordidez de tua própria vida!".

Desse excerto da peça de Sófocles gostaríamos de destacar duas ideias que nutrirão as argumentações posteriores. A primeira diz respeito à condição "física" de Tirésias. Além do peso da idade e suas naturais limitações, Tirésias é cego. Mas isso não o impede de "ver"; afinal, ele é um "vidente". Temos aqui uma intrigante configuração: Tirésias é um "vidente cego". Isso significa que os conteúdos de verdade que Tirésias dispõe e que "esclarecem" as etapas da vida (e do destino) de Édipo, não são conteúdos "visuais", não são conteúdos que possam ser capturados pela "unilateralidade do sujeito que olha". Quem não enxerga é Édipo, apesar de ter os olhos em funcionamento pleno. A figura tirésica afronta uma tendência alimentada na cultura ocidental de que a verdade se funda no "olhar", numa supremacia da visão sobre os outros sentidos, confirmada na expressão: “só acredito, vendo!”. A “lógica do olhar" está muito próxima da lógica teórica, mediada por um sistema simbólico estável e denotativo. É a lógica da teoria tradicional do conhecimento, que vê na ciência a sua expressão mais acabada. Detalharemos as características do sistema simbólico da ciência mais adiante. Por agora basta apenas mencionar sua semelhança com o "olhar" contraposta pela promessa tirésica de existirem outras possibilidades de "esclarecimento" do mundo. A presença de um "vidente cego" no interior da obra de Sófocles, como portador da verdade e onde se deposita a esperança de Tebas, é um manifesto sobre as potencialidades dos meios não diretamente ligados à "lógica do olhar" como instâncias de produção e transmissão de conhecimentos.

Outra tese que podemos examinar é sobre a natureza das verdades portadas por Tirésias. Tais conteúdos não estão legitimados pelo "olhar". O destino que constituiu a vida de Édipo não foi, por assim dizer, registrado por uma câmera objetiva e arquivado num filme. Desvelado pelo "vidente cego", tal destino precisa ser "reconhecido" pelo ouvinte. A peculiaridade desse conteúdo "não visual" exige, como contrapartida, um "ouvido" capaz de reconhecer valor cognitivo no que lhe é apresentado. Só assim a verdade vem à tona de modo completo. Os conteúdos "invisíveis" não podem ser 
simplesmente traduzidos para o "olho", atendendo sua sede de imagem. Os conteúdos "invisíveis" só podem apresentar-se a um "ouvido" que seja capaz de reconhecê-los.

As inquietações propostas pela figura tirésica nos levam a pensar sobre relações entre a arte, de modo especial a música, e a ciência. Ainda que existam especificidades claras em cada uma dessas expressões do pensamento humano, ambas são experiências estruturantes, experiências de simbolização e compreensão do mundo, ambas são portadoras de conteúdos de verdade. Neste particular, compartilhamos com a posição de Nelson Goodman ${ }^{2}$ que dilui qualquer hierarquia entre as formas de conhecimento. Os traços gerais de sua epistemologia, pano de fundo de nossa argumentação, amparam o objetivo de demonstrar o valor cognitivo da arte e da música, recusando a noção que experiências com elas são apenas jogos de "habilidades" ou ocasiões "emocionais". Por conta da natureza mais "geral" desse artigo, preferimos não abordar detalhadamente - a não ser quando isso se fez muito necessário - as diferenças entre a música e as demais artes (pintura, escultura, arquitetura, dança, etc.). Preferimos destacar os que colocam as expressões artísticas no mesmo patamar da ciência, tornando-as igualmente imprescindíveis para o avanço do conhecimento.

\section{Arte e ciência: simbolizar e compreender}

Sob o ponto de vista epistemológico, a tese central de Goodman é a do construtivismo. Para Goodman, tudo o que conhecemos do mundo são versões, prerrogativa impede radicalmente a possibilidade de garantir a existência e a descrição de um mundo fora de nós. A existência de um mundo fora de nós, uma "coisa em si" no modelo kantiano, é uma possibilidade tão somente especulativa. Nem o modo como o mundo é dado, nem

\footnotetext{
2 Nascido em 1906, no estado americano de Massachussetts e falecido em 1998, Nelson Goodman acumulou uma rica biografia ligada às artes que incluiu desde uma intensa produção teórica até a direção de uma galeria (Walker-Goodman Art Gallery) e de um projeto (Project Zero, em Harvard) voltado à compreensão do pensamento criativo nas artes, nas humanidades e nas ciências. No campo teórico, suas obras mais importante são: The structure of appearance (1951), Fact, Fiction and Forecast (1954), Languages of art (1968), Problems and projects (1972), Ways of worldmaking (1978) e Of mind and other matters (1984).
} 
nenhum modo de ver ou figurar ou descrever nos conduz ao modo como o mundo é (GOODMAN, 1972). 0 que fazemos é "construir mundos", versões que preenchem a vida de sentido. A conseqüência disso é que nós não podemos chegar ao modo como o mundo é perguntando pelo modo mais realístico de representá-lo. Os modos de ver e figurar são muitos e variados; alguns são fortes, efetivos, úteis, intrigantes ou sensíveis; outros são fracos, cômicos, desanimados, banais ou confusos (GOODMAN, 1972). Uma versão-de-mundo ou construção-de-mundo é um sistema que dá forma e significatividade ao que julgamos ser a visão de um mundo separado de nós.

Construímos versões de acordo com a dinâmica dos problemas, demandas e convenções que vão aparecendo num setor da vida, seja na ciência, na arte ou na filosofia. A "força de atração" de um sistema simbólico se faz sentir até mesmo na mais elementar percepção: não há um olhar é neutro e/ou desinteressado; percebemos o que o sistema simbólico com o qual estamos operando permite perceber. É por isso que a epistemologia de Goodman, além de construtivista, é pluralista e relativista. Pluralista porque sustenta que há uma riqueza de versões-de-mundo as quais, sob o ponto de vista de sua validade, são igualmente importantes. Tanto as teorias científicas, as teorias filosóficas, as composições musicais, os filmes, as demais artes e mesmo a relação mais direta e sensível que temos com as coisas, compõem essa gama de versões. A distinção entre as versões se dá pelas características internas e não pela função.

É de forma moderada que relativismo se apresenta na epistemologia de Goodman. Para Goodman (1972), nenhuma versão é mais correta que a outra. Nenhuma delas pode nos dizer como o mundo é, mas cada uma delas nos diz um modo como o mundo é. Isso não significa que não possam existir sistemas simbólicos incorretos, mas sim que, entre os sistemas simbólicos corretos, nenhum é melhor que o outro: “Todas as versões verdadeiras que se encontram em conflito são verdadeiras em mundos diferentes. Estes, por sua vez, devem ser entendidos como mundos reais e não como mundos possíveis" (D’OREY, 1995, p. 10. Grifos do autor.). Os sistemas simbólicos são corretos na medida em que desenvolvem programas de correção interna amparados em três fatores: consistência, constância e sucesso continuado das suas categorias. 
Considerando a diversidade dos sistemas simbólicos, a concepção tradicional de saber e/ou conhecimento, como um conteúdo expresso em linguagem verbal literal e que exige verdade, crença e justificação, precisa ser revisada. Para Goodman (1995) o saber é progresso na compreensão. A compreensão, por sua vez, abrange tanto as nossas possibilidades de investigar e inventar, o processo cognitivo através do qual construímos mundos de qualquer espécie como o resultado obtido por essas construções.

Em linhas gerais, um sistema simbólico é um esquema (conjunto de símbolos) aplicado a um campo de referência (conjunto de referentes). Ser um símbolo não é uma propriedade intrínseca de um objeto, mas, sim, uma função dentro de um sistema. Tal função é de referir, estar por algo. Algo se torna símbolo no interior de um sistema simbólico. A rigor, tudo pode funcionar como símbolo, embora existam certos objetos como as palavras, os sons (de uma escala musical, por exemplo) e as imagens, que, com mais frequência, desempenham essa função. Um símbolo é uma capacidade, cujos limites e propriedades são inteiramente determinados pelo sistema no qual se encontra funcionando ${ }^{3}$. Uma nota musical, por exemplo, funciona bem mais frequentemente como símbolo do que a lua que, por sua vez, funciona mais frequentemente como referentes. Entretanto, a lua, para o romântico ou para o astronauta, pode simbolizar sentimentos, desafios ou conquistas.

Os termos "simbolização" e "referência" são usados por Goodman com um sentido bastante amplo, envolvendo a relação entre um símbolo e aquilo pelo qual está (seja de qual forma for). Qualquer sistema simbólico, seja da arte ou da ciência, possui uma estrutura sintática - que estabelece a natureza e o regramento dos símbolos - e uma estrutura semântica - que estabelece a relação entre os símbolos e seus referentes.

\footnotetext{
${ }^{3}$ A dinâmica do símbolo no interior de um sistema específico é análoga ao que Wittgenstein, nas Investigações Filosóficas, denominou como "significação de uma palavra" (WITTGENSTEIN, 1991, p. 28). Assim como só conseguimos apreender a dinâmica do símbolo conforme o sistema onde atua, só sabemos o significado de uma palavra se sabemos "usá-la" num jogo de linguagem específico.
} 
A referência de um símbolo pode aparecer de duas maneiras: por denotação ou por exemplificação ${ }^{4}$. A denotação ocorre quando o símbolo se aplica a algo diretamente, quando se refere diretamente a um objeto. 0 objeto, aqui, é a sua extensão, e o símbolo poderia levar o nome de etiqueta. Um exemplo de denotação ocorre no uso dos nomes próprios: quando afirmamos que o nome "Arthur" refere o Arthur, fica estabelecida uma relação de denotação entre uma etiqueta, a palavra "Arthur", e um referente, o Arthur propriamente dito. A exemplificação, por sua vez, ocorre quando o símbolo é uma amostra da etiqueta, um caso de alguma coisa. Fica evidente que, para haver uma exemplificação, tem de ter ocorrido uma denotação anterior. Uma palavra como "filho" pode denotar um filho específico, o meu filho, por exemplo; por isso, posso apresentar o meu filho como uma amostra de "filho".

Outro aspecto importante para estabelecer as diferenças e semelhanças entre arte e ciência é a é a distinção entre esquema e domínio. Esquema é um conjunto de símbolos, enquanto o domínio é o conjunto dos referentes. Um sistema denotativo - como o da ciência - usa um esquema formado por etiquetas cujo domínio é um conjunto de objetos. Num sistema exemplificativo - como o da arte - o esquema é composto por um conjunto de objetos que funcionam como símbolos e o domínio, nesse caso, é composto por um conjunto de etiquetas.

Quando se admite a ideia que a compreensão designa um processo cognitivo através do qual construímos versões-de-mundo de qualquer espécie, fica fragilizada a concepção que opõe arte e ciência. Construir mundos através de sistemas simbólicos é uma tarefa comum a esses dois territórios da compreensão humana: “Ambas podem ser corretas ou incorretas de diferentes maneiras; ambas podem ter um domínio de aplicação universal: para ambas existem critérios de aceitabilidade, e testes e experiências a que podem ser submetidas; em nenhum caso há garantias definitivas" (D’OREY, 1995, p. 17).

\footnotetext{
${ }^{4}$ Outras relações de simbolização, tais como a representação, a descrição e a citação são formas de denotação; já a expressão é uma forma de exemplificação. Em outros casos, como na alusão, intervêm tanto a denotação como a exemplificação. Essa tipologia das relações de simbolização é detalhada em Linguagens da arte, principalmente nos capítulos II e IV.
} 
Mesmo realizando tendo objetivos comuns - construir mundos -, arte e ciência possuem, obviamente, diferenças fundamentais. Tais diferenças, entretanto, não se originam da ultrapassada dicotomia que põe, do lado da arte, a beleza, a intuição e a emoção e, do lado da ciência, a verdade, a racionalidade e a lógica. As diferenças estão nas peculiaridades dos processos simbólicos que constituem cada um dos sistemas. Os sistemas da ciência são, geralmente, construídos por processos denotativos, linguísticos e literais, onde os símbolos possuem um referente direto e único. Na arte, os sistemas são mais ricos, através de meios não literais e de processos exemplificativos. No caso da música os sistemas são construídos através de símbolos não-verbais, que são densos e saturados e onde o referente é indireto e múltiplo. No entender de Goodman, todas as outras diferenças entre arte e ciência decorrem destas.

A ciência só aceita sistemas que permitem segurança na determinação dos resultados experimentais e a busca de consenso na comunidade científica, daí decorre sua preferência por sistemas denotativos e verbais. Já a arte tende a tomar a sério a ambiguidade e as diferenças das sensibilidades como características que enriquecem sua interpretação. A arte privilegia a densidade, a saturação, a exemplificação e a referência múltipla e complexa, características que são denominadas por Goodman como "sintomas do estético"5. Tais características opõem-se à articulação, atenuação, denotação e referência simples e direta, que são "sintomas do não-estético", ou seja, da linguagem científica.

\section{A exemplificação como "linguagem da arte"}

A exemplificação é o traço mais fundamental dos mundos construídos pela arte. A exemplificação é um tipo de relação simbólica em que o objeto refere algumas das propriedades que possui. Ela permite compreender, segundo Goodman, a função referencial presente em todas as obras de arte, inclusive as mais minimalistas e

\footnotetext{
${ }^{5}$ Uma explicação mais detalhada dos "sintomas do estético" pode ser encontrada em Linguagens da Arte, no capítulo VI, seção 5 e, de maneira breve, em Modos de fazer mundos, capítulo IV.
} 
abstratas. Quando observamos um quadro de Mondrian - como, por exemplo, a Composição em vermelho, amarelo, azul e preto, de 1921 -, mesmo na falta de uma referência denotativa, podemos encontrar exemplificações de cores e de formações geométricas. A função exemplificativa da arte permitiria assegurar que todas as obras são símbolos e referem algo, mesmo quando não denotam nada.

No capítulo IV de Modos de fazer mundo, sob o título de "Quando há arte?", Goodman expõe mais pormenores sobre a dinâmica da função simbólica da arte. Segundo os formalistas, o que importa numa obra de arte são suas propriedades em si mesmas e, exatamente por isso, a arte pura deveria evitar a simbolização. A simbolização desviaria a atenção de suas propriedades intrínsecas. 0 que Goodman propõe é que a posição formalista está errada ao julgar que a simbolização significa sempre uma referência a algo exterior às obras de arte. Considerando o exemplo de uma pintura "verdadeiramente pura", Goodman demonstra que, por mais que procuremos, não vamos encontrar nela uma propriedade interna totalmente específica. Propriedades como cores e formas não são exclusivas da obra de arte supostamente "pura"; elas põem a obra sempre em contato com o exterior e com outras obras. A cor branca ou um determinado som não é algo que só encontramos num quadro de Mondrian ou numa música de Hermeto Pascoal; podemos experimentar tais coisas em várias outras oportunidades perceptivas fora do âmbito da arte.

Para ilustrar seu argumento, Goodman propõe uma análise do que acontece quando nos vemos diante de uma amostra de tecido:

\footnotetext{
Considere-se de novo uma vulgar amostra de tecido no catálogo de amostras de um alfaiate ou de um estofador. É improvável que seja uma obra de arte, que represente pictoricamente ou exprima alguma coisa. É simplesmente uma amostra - uma simples amostra. Mas de que ela é uma amostra? Da textura, da cor, da tecedura, da grossura, das fibras de que é feita...; tudo o que importa nesta amostra, somos tentados a dizer, é que ela foi cortada de uma peça de tecido e tem as mesmas propriedades do resto do material. Mas isso seria demasiado precipitado. (GOODMAN, 1995, p. 109).
}

A experiência com o tecido sustenta que uma amostra de tecido é amostra (ou exemplo) de apenas algumas propriedades e não de outras. Amostras de tecido exemplificam cores, textura e padrão, mas não exemplificam forma e tamanho. Ou seja, exemplificam 
apenas aquelas propriedades que possuem e referem naquela circunstância específica. Se expandirmos as conclusões para o domínio das artes, verificamos que algumas obras de arte - de modo especial as mais abstratas - também exibem suas próprias propriedades, selecionando algumas para despertar nossa atenção. Porém, não há, ao contrário das amostras de tecido, critérios e procedimentos seguros para determinar o que uma obra de arte exatamente exemplifica ou representa. É ao trabalho reflexivo e crítico que compete tal tarefa, que, como conditio sine qua non, precisa conhecer o sistema a que ela pertence. 0 próprio Goodman (1995, p. 110) conta uma anedota sobre o que pode ocasionar o desconhecimento de um sistema simbólico mesmo na ocasião banal de escolher tecidos por intermédio de uma amostra:

\begin{abstract}
A Sra. Mary Tricias analisou um catálogo de amostras, fez a sua seleção e encomendou da sua loja de tecidos favorita material suficiente para o seu sofá e cadeira estofados - insistindo que esse material deveria ser exatamente igual à amostra. Quando a encomenda chegou ela abriu-a avidamente e ficou consternada quando várias centenas de peças com $6 \mathrm{~cm} \times 10 \mathrm{~cm}$, com lados cortados em ziguezague exatamente como a mostra, esvoaçaram pelo chão. Quando telefonou para a loja, protestando ruidosamente, o proprietário replicou, magoado e aborrecido: "Mas, Sra, Tricias, a senhora disse que o material devia ser exatamente como a amostra. Quando ele chegou ontem da fábrica, mantive aqui os meus empregados metade da noite a corta-lo para ficar exatamente como a amostra".
\end{abstract}

A "leitura" de um sistema simbólico supõe uma "competência", uma postura "nãoinocente" (BORETZ, 1970, p. 546) já que um sistema pode ser mais "sofisticado" que outro. A interpretação de um sistema simbólico como o da arte está ligada diretamente a experiências anteriores bem sucedidas. A "falha" no processo de compra do tecido por Mary Tricias tem sua causa no desconhecimento da lógica geral do sistema e da condição assumida por cada símbolo.

\title{
Tirésias "vê"!: o valor cognitivo da arte
}

Uma primeira forma para sustentar o valor da arte, sugere Goodman, seria a satisfação. Tal argumento, porém, não é consistente: a ideia que a arte é boa porque é satisfatória é uma redundância. Afirmar que uma obra de arte é satisfatória ou boa é também admitir nela certa capacidade de realizar uma função: "ser satisfatório é, em geral, 
relativo a uma função de propósito" (GOODMAN, 2006, p. 269). Mas qual seria, então, este propósito? Como já mencionamos anteriormente, as obras de arte são sistemas simbólicos e, como tais, sua função é a mesma de todos os sistemas simbólicos: "as obras de arte ou os seus exemplares desempenham uma ou mais de entre um conjunto de certas funções referenciais: representação, descrição, exemplificação, expressão" (GOODMAN, 2006, p. 269). A questão é saber para qual propósito tal simbolização serve.

Em busca de uma resposta precisa à questão da função do sistema simbólico da arte, Goodman analisa três possibilidades. A primeira é que essa simbolização exercita e desenvolve competências para enfrentar futuras contingências, tornando-nos mais aptos para sobreviver, conquistar e ganhar. A experiência estética "torna-se um exercício de ginásio, sendo as imagens e sinfonias os halteres e sacos de boxe que usamos para fortalecer os músculos intelectuais" (GOODMAN, 2006, p. 269). A arte teria, por decorrência, o "poder pedagógico" de canalizar a energia em excesso afastando-nos do que é destrutivo, perfazendo um inusitado modelo platônico de disciplina. A segunda possibilidade é quase oposta e bem mais simplista: a simbolização é uma propensão natural, tal como é o jogo. Jogar e simbolizar são empreendimentos divertidos $\mathrm{e}$ isso atrai naturalmente o homem. Uma terceira possibilidade, para além da oposição entre o prático e o divertido, seria a comunicação. Utilizaríamos o sistema simbólico da arte para comunicar fatos, pensamentos, sentimentos e percepções.

Não resta dúvida que cada uma destas explicações para o papel da arte como atividade simbólica - seja exercício (ginástica), brincadeira (jogo) ou comunicação (conversa) -, contem aspectos verdadeiros. 0 que as três ignoram, defende Goodman, é que a motivação maior da atividade simbólica é a curiosidade e o objetivo é a compreensão e o esclarecimento. As três explicações supõem uma "cegueira", uma incapacidade da arte em ser "geradora de conhecimento". Mesmo quando é identificada com a comunicação, a arte não é vista como "conteúdo", mas apenas como "forma", como "medium", como expressão de uma verdade que, no fundo, não lhe pertence. 


\begin{abstract}
O uso de símbolos para além da necessidade imediata faz-se em nome da compreensão e não da prática; o que compele é a ânsia de conhecer, o que delicia é a descoberta e a comunicação é secundária relativamente à apreensão e formulação do que comunica. 0 objetivo principal é a cognição em si e para si; o caráter prático, o prazer, a compulsão e a utilidade comunicativa dependem todas deste objetivo. (GOODMAN, 2006, p. 271).
\end{abstract}

Uma obra de arte, do mesmo modo que uma teoria científica, permite construir associações, distinções e categorizações, contribuindo para a organização da nossa experiência com as coisas, conosco mesmos e com os outros. Se é por causa de sua função cognitiva que a arte adquire valor, não é nem mais nem menos valiosa que a ciência ou qualquer outra forma de criar mundos. 0 que a epistemologia de Goodman propõe é que a arte, apesar de ter especificidades internas, não tem um valor específico; cada obra de arte é mais um mundo que construímos.

Qual seria, então, a especificidade (ou excelência) dos objetos estéticos? Para responder tal questão, em primeiro lugar é preciso registrar que a subsunção do estético à função cognitiva não implica em descartar o sensorial e o emotivo: “[...] que conhecemos através da arte tanto se sente nos ossos, nervos e músculos como é apreendido pela mente, que toda a sensibilidade e resposta do organismo participa na invenção e interpretação de símbolos" (GOODMAN, 2006, p. 272). Em segundo lugar é preciso recordar que os sistemas simbólicos têm modos específicos de organizar o mundo e que as características internas que nos fazem preferir um sistema são denominadas de critérios de correção. De fato, ainda no capítulo "Sobre a correção da apresentação", de Modos de fazer mundos, Goodman examina detalhadamente o tema da verdade propondo que tal conceito é uma questão de ajustamento entre versões, numa referência facilmente aplicável às teorias científicas. Tal ideia de verdade, no entanto, pode ser prescindida quando se avalia os sistemas da arte, onde o critério de qualidade passa a ser a correção da amostra (ou do exemplo). Procurando agora formalizar a resposta à questão formulada no início do parágrafo, se levamos em conta que um dos sintomas do estético é a exemplificação, relação em que o símbolo funciona como amostra (exemplo), conclui-se que símbolos estéticos são tão mais corretos quanto mais projetáveis ou representativos (GOODMAN, 1995). A projetabilidade ou 
representatividade é a capacidade de exemplificar predicados (etiquetas) que podem aplicar-se a novos casos. Uma amostra é correta, prossegue Goodman (1995, p. 190) quando pode ser "[...] projetada para o padrão, mistura, ou outra característica relevante do todo ou de amostras posteriores".

A projetabilidade ou representatividade requer a boa prática de interpretação de amostras, que, por sua vez, depende do hábito, da revisão contínua, da atenção ao contexto e da convivência com a invenção e a frustração. Quando há densidade - um dos sintomas do estético - num sistema de símbolos, “[...]a familiaridade nunca é completa e final; outro olhar pode sempre desvelar novas sutilezas significativas. Além disso, o que lemos num símbolo e através dele varia com o que trazemos conosco" (GOODMAN, 2006, p. 272). Através dos sistemas simbólicos em geral, e de uma maneira bem particular com os sistemas simbólicos da arte, não só compreendemos melhor o mundo como compreendemos e reavaliamos os "mini-mundos" que nos constituem.

\section{Referências}

1. BORETZ, Benjamin. (1970). Nelson Goodman's languages of art from a musical point of view. The Journal of Philosophy, New York, v. 67, n. 16, p. 540-552.

2. D'OREY, Carmo. (1995) Introdução. In: GOODMAN, Nelson. Modos de fazer mundos. Porto: ASA, p. 5-29.

3. GOODMAN, Nelson. (1997) Languages of art: an approach to a theory of symbols. Indianápolis: Hackett.

4. ___ (2006) Linguagens da arte: uma abordagem a uma teoria dos símbolos. Lisboa: Gradiva.

5. ___ (1995) Modos de fazer mundos. Porto: ASA.

6. ___ (1972) Problems and projects. Indianápolis/New York: The Bobbs-Merril Company.

7. SÓFOCLES. (1998) A trilogia tebana: Édipo Rei - Édipo em Colono - Antígona. 8. ed. Rio de Janeiro: Jorge Zahar. 
8. WITTGENSTEIN, Ludwig. (1991) Investigações filosóficas. 5.ed. São Paulo: Nova Cultural.

Nota sobre o autor

Gerson Trombetta, possui graduação em Filosofia Licenciatura Plena pela Universidade de Passo Fundo (1993), mestrado em Filosofia pela Pontifícia Universidade Católica do Rio Grande do Sul (1998) e doutorado em Filosofia pela Pontifícia Universidade Católica do Rio Grande do Sul (2006). Atualmente é professor titular e pesquisador da Universidade de Passo Fundo na área de Filosofia e no Programa de Pós-Graduação em História. Tem experiência na área de Filosofia, com ênfase em Filosofia da Arte e da Cultura, Formação de Professores, Filosofia da Linguagem e Teorias da História. 